\title{
Public Transportation Design as Grassroots Pedagogy
}

\author{
SERGIO PALLERONI, Professor and Director, Center for Public Interest Design
}

Portland State University

In the spring of 2014, the Center for Public Interest Design (CPID) was approached by the Sacramento Area Council of Governments to begin the process of exploring how public interest design could be used to address the needs of some of Sacramento's most disinvested and environmentally impacted neighborhoods. This collaboration began at a crucial time for California as the State was in the process of implementing the first cap and trade legislation in the US. A significant percentage of funds collected through the sale of carbon tax credits associated with this legislation are required to be invested in disadvantaged communities. This paper proposal examines the potential for design to play a role in identifying social investment opportunities to create healthier communities through the CPID's work with students in Central California.

In the course of nearly five years the work of CPID for the Councils of Governments in California to engage the new carbon reinvestment legislation has led to a focus on transportation design. Access to food, health care, education, and recreation, now standard public health metrics to a healthy and productive life, have emerged as the key goals of the reinvestment act. Access to public transportation is currently not equitable in much of California and often reflects more the economic and political assets of the community rather than need. In an effort to distribute the impact of the carbon tax to those in need, and build the political capacity of these communities, CPID's efforts have focused in the last two years to the creation of guide, and case studies, for future community transportation stations that serve as needed assets, and are co-produced by the stakeholders of each community in collaboration with design professionals and state agencies. The guides act as both a framework by which architects, engineers and transportation systems can involve communities in the process of a design that reflects their community and needs, as well as thought frames for changing the perception of communities and local transportation systems on the role that these stations can play in the community (i. e. The bus station as community center).

With fieldwork now an accepted and broadly embraced form of pedagogy in Schools of Architecture the experience of CPID offers a model of engagement that has not been significantly developed within the academy but offers promise. Every community in the US and North America in general has a transportation system, and many are in need of updating and reconnection to the communities they serve. As such this offer academics an opportunity for community engagement and public interest design as well as and course pedagogy in a range of subjects areas ranging from tectonics to material systems and human centric design that addresses all ability levels. The presentation will both share the strategies and methods of engagement as well as the lessons learned in the process of both changing perceptions and attempting to build the first of these station for communities in need.

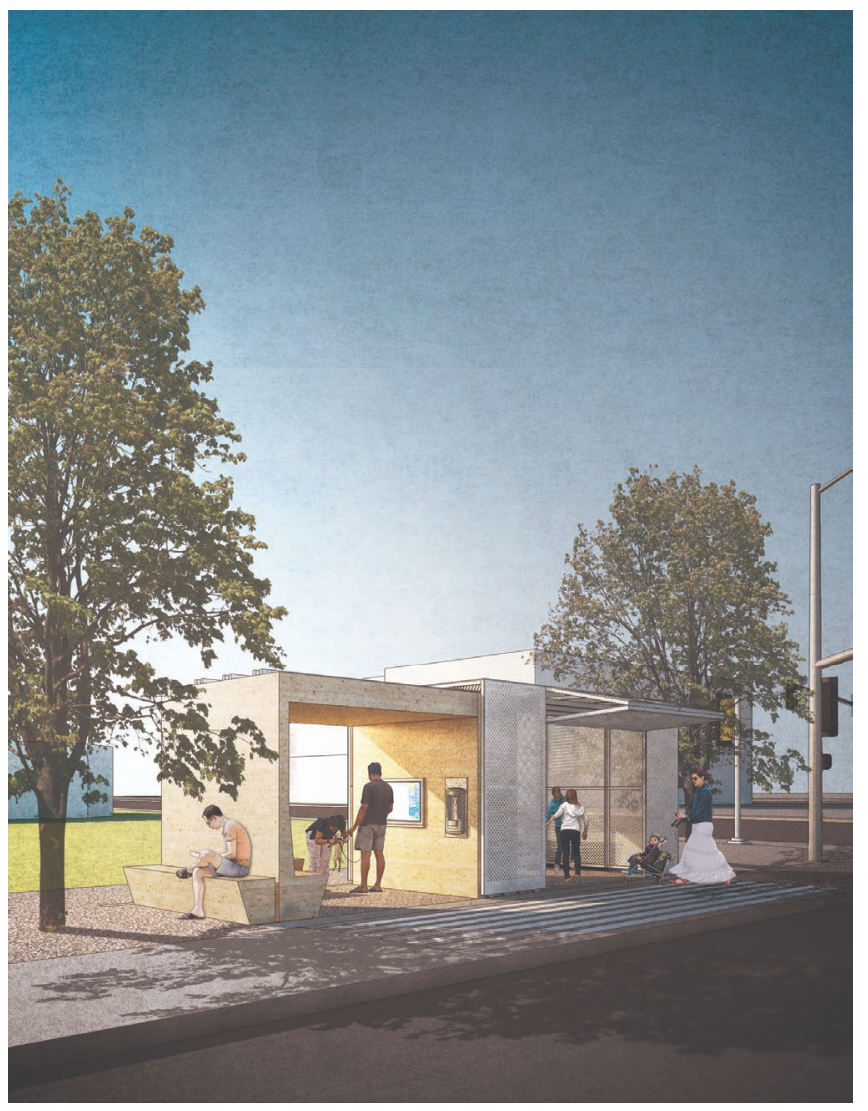

Figure 1. Bus Station as Community Center Del Paso Heights (CPID). 


\section{ACTORS}

The Center for Public Interest Design (CPID) is a research, education, and community design center whose mission is to investigate, promote, and engage in inclusive design practices that address the growing needs of underserved communities worldwide through sustainable methods. Based in the Portland State University (PSU) School of Architecture, the CPID fosters opportunities for transdisciplinary collaboration among faculty, professionals, community members, and students. CPID faculty Sergio Palleroni, Todd Ferry and BD Wortham-Galvin began working with the Sacramento Area Council of Governments (SACOG) in the Spring of 2014 to begin the process of exploring how public interest design can be used to address the needs of some of Sacramento's most disinvested neighborhoods. The goal was to use the power of design to promote healthier and more equitable places and people, through within the funding parameters of the cap and trade legislation that was in 2014 beginning to become available to disinvested communities.

\section{CONTEXT}

Immediately prior to the CPID beginning its research and building its relationship with potential collaborators, there was an ad campaign emphasizing the disparate life expectancy of Californians based on where they live within the state. The campaign was an effort of the California Endowment, a nonprofit focused on improving the health of Californians, to raise awareness about inequality in the state. ${ }^{1}$ The billboards and print ads compared two different places, providing a zip code and average age of death in each, accompanied by the question, "Did you know your zip code is a better predictor of your life expectancy than your genetic code?"2 This provocative question is supported by research that substantial differences of as much as a decade or more in life expectancy can be found in areas just a few miles from one another, including in Sacramento.

This revelation about zip codes as predictors of health underscores unsettling realities of our growing income inequality in the US, and was highlighted in a report published by the American Human Development Project titled A Portrait of California 2011 (Burd- Sharps and Lewis, 2011). ${ }^{3}$ This report uses the American Human Development Index to provide a framework by which to evaluate the success of a population outside of conventional monetary-based metrics, such as GDP. While health is just one of three major categories in the human development index, the others, access to knowledge and standard of living, also have a direct impact on health outcomes. These collectively indicate that one's zip code is indeed a primary determinant of health. ${ }^{4}$

While extreme inequities underscored in the report due to factors such as race and ethnicity, gender, nativity, and geography impacting the socio-economic and environmental conditions were disheartening, Californians concerned with social justice were finding new cause for cautious optimism. In 2012, the Legislature passed Senate Bill 535 and Assembly Bill 1532, requiring State and local agencies to invest in and improve disadvantaged communities using funds from the Greenhouse Gas Reduction Fund (GGRF). Commonly known as cap and trade strategies, this program places a limit, or cap, on green-house gas emissions by issuing a limited number of emission allowances (equal to the limit that will be reduced progressively) to sources responsible for 85 percent of the total emissions in California. The California Air Resources Board now conducts quarterly auctions for available allowances, with revenues from these auctions collected in the GGRF.

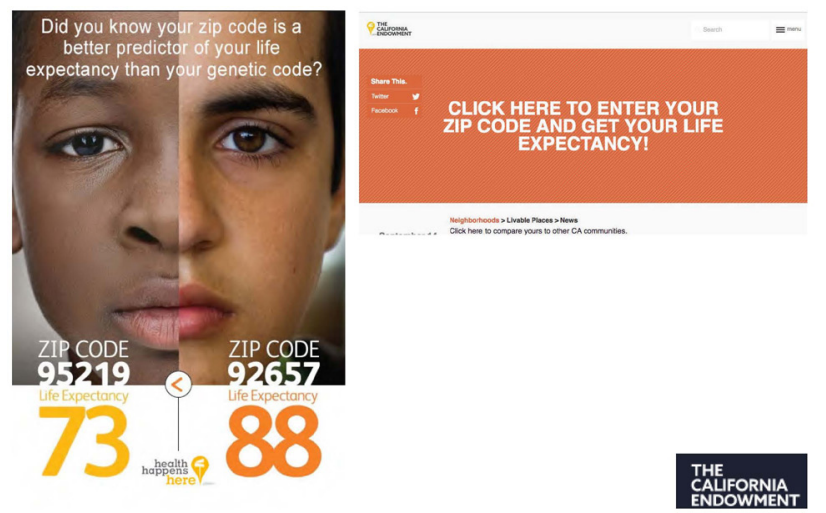

Figure 2. Portrait of California Ad and Website.

Of the several billion dollars in annual proceeds from this initiative, this legislation states that a minimum of 25 percent of proceeds is required to go to projects that benefit disadvantaged communities, with at least 10 percent of the total funds supporting projects located within disadvantaged communities. (In 2015, it was reported that 39\% of all projects and $\$ 356 \mathrm{M}$ were dedicated to disadvantaged communities, and the amount has grown yearly). ${ }^{5}$ The goal of the funds are to improve public health, quality of life, and economic opportunity in California's most environmentally impacted communities, while at the same time reducing pollution that causes climate change. While the state had designated funding for disadvantaged communities in 2012, it wasn't until 2014 that the California Environmental Protection Agency (CalEPA) fully defined what constituted a disadvantaged community for these purposes.

CalEPA created the CalEnviroScreen 2.0 tool to inform their process of identifying disadvantaged communities by using a "science-based method for evaluating multiple pollution sources in a community while accounting for a community's vulnerability to pollution's adverse effects (CalEPA, 2014)." 6 Like the Human Development Index, the CalEnviroScreen tool acknowledges that traditional metrics of evaluating 
environmental health impacts are often insufficient to tell the whole story, and socio-economic factors and other considerations were included in the evaluation made up of 19 individual indicators. This is a significant step in considering public health. As is noted in the report, "Existing research on environmental pollutants and health risk has consistently identified socioeconomic and sensitivity factors as 'effect modifiers.' For example, numerous studies on the health effects of particulate air pollution have found that low socioeconomic status is associated with about a 3-fold increased risk of morbidity or mortality for a given level of particulate pollution (Samet and White, 2004)."7 The CalEnviroScreen tool provides a clear means to identify disadvantaged communities eligible for investment of cap and trade proceeds to begin addressing some of the inequities and determinants of health based on zip code outlined in A Portrait of California.

The driving question for the faculty and students at the Center for Public Interest Design entering this complex context was, "Is there a role for design to play in the creation of healthier communities through a participatory process that identifies opportunities and provides visions for strategic investment in Sacramento's underserved communities?"

\section{ON THE GROUND}

CPID and SACOG began their collaboration in the spring of 2014 with a listening tour, meeting with stakeholders and community leaders in Sacramento's most disadvantaged communities. Following an intensive period of research, stakeholder meetings, and site visits, the team identified two ideal community partners in the neighborhoods of Del Paso Heights and South Sacramento. The community organizations in these neighborhoods (Mutual Assistance Network in Del Paso Heights and La Familia in South Sacramento) had incredible leadership, the trust of their communities, and the desire to pursue projects together, all qualities needed to support a successful effort.

The two neighborhoods differ from one another significantly enough in demographics, geography within the city, and specific concerns, while sharing similar challenges like, lack of education, underemployment, and violence, that together they can inform design systems that are flexible and able to be employed in a range of neighborhoods throughout the city. South Sacramento is predominantly Latino, while Del Paso Heights has a larger percentage of African American and Asian American citizens. A goal of developing potential design systems within these neighborhoods would certainly have to reflect the cultural richness in these areas and not simply propose a generic one-size-fits-all solution.

CPID faculty developed a series of strategies for engaging the community and approaching the issues that emerged as being most crucial to addressing environmental and economic marginalization they suffered. This framework established a method of:
- Multi-stakeholder participation through an open, transparent, and iterative design process.

- Integration of physical, social, environmental, and economic strategies in single interventions, recognizing a need to think beyond individual structures to include design of programs, processes, and enterprises with the help of a multi-disciplinary team.

- Networked interventions of small-scale projects as catalysts and strategic elements to inform larger community goals.

These strategies were brought into studios at PSU's School of Architecture beginning in the fall of 2014 where studios were taught concurrently by project faculty over the next four year. The studios consisted of fourth year undergraduates students engaging urban design and graduate students looking at urban design, architecture and tactical urbanism, resulting in at times up to 45 students working on the initiative per academic period. Students had the opportunity to travel to Sacramento and meet with community leaders, government officials, and project stakeholders, with grant support, before beginning the process of proposing design responses. A series of mapping exercises documented assets and challenges in the neighborhoods, informed by community engagement activities. In Del Paso Heights, for example, students set up engagement tools aimed at understanding and documenting community hopes and concerns at the neighborhood's annual Harvest Festival (the most well-attended community event of the year), a tradition the CPID has continued in subsequent years.

\section{DESIGN}

The design responses in this first studio ranged from transportation systems to allow communities to better connect to needs, to recreation centers and business incubators, to street improvements and systems of occupying vacant lots with pop-up shops. Ultimately, the project partners have chosen to move forward with several strategic ideas that were developed in the studios, including the design of a series of bus stops which explored the possibility that a bus stop could double as a micro community center, or facility addressing other pressing community needs. The bus stops seek to take advantage of funding available for transportation systems through cap and trade proceeds, while responding to community desires for spaces and amenities that might not yet be achievable at a larger scale. For example, one early bus stop proposal by PSU graduate student, Nicole De Jong envisioned a core bus shelter that remained in place while a metal screen shell extends to create a secondary space of equal size to be programmed by the community, such as a place for local entrepreneurs to sell food and crafts, an outdoor classroom for a local youth group, or a safe gathering space (see Figure 3 ). We see this approach as a strategic way to begin working with community members on specific interventions that can serve as a proof of concept for other investment. 
Following these initial design studios, CPID staff, students, and interns have continued to explore opportunities for design to play a role on a variety of scales, including further developing concepts for tactical bus stops, and more recently light rail stations on the regional transit system. The design strategies for the bus stops emphasize a fully participatory process with the community, and have ranged from a kit of parts that allow the community to choose the elements they would like in their neighborhood, to a system of building the stops with the community using reclaimed materials found within the area. The bus stops address issues of safety, environmental impact through increasing choice ridership of public transportation, enhancing community identity, and responding to the need for various community amenities. While we are developing a system for dozens of these bus shelters to be designed, funded, and built, we imagine that no two will be the same, reflecting the unique needs and character of each community. A significant reason for this is that the system the CPID is proposing empowers the community to take control of the project for themselves, and collaborate as co-producer, or curators of the design programming and design process with local designers and transportation firms.

\section{COMMUNITY PROCESS: PROGRAM SELECTION}

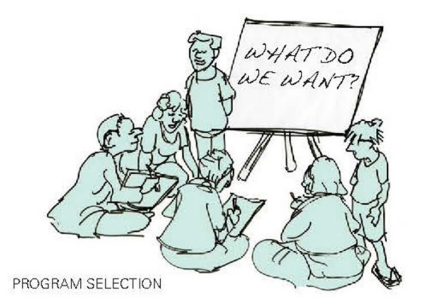

The neighborhood community is the expert on what types of programs would best serve the residents and
the type of design that will best reflect the neighborhood. The inten evelopment of the acsis stops hrough a series of workshops with local residents. The workshops offer (the as the physical aesthetios af we given Oasis Stop. In addition these workshops offer potential funding and service partners an opportunity are hoping to serve.
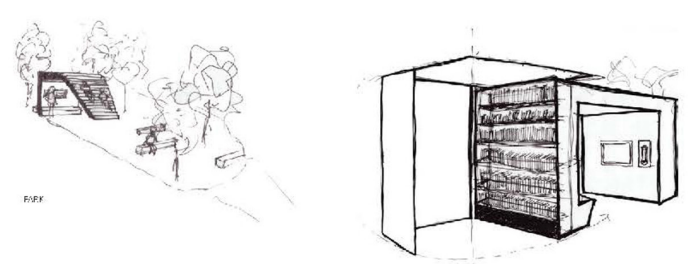

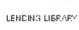
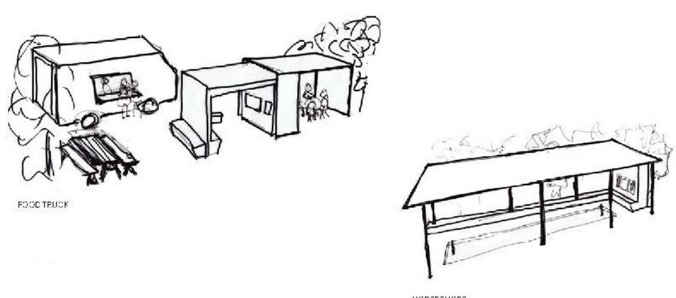

\section{TESTING THE PROPOSED PROCESS THROUGH PILOT APPLICATIONS}

Starting in 2016 CPID was invited to design the first transit stops based on the model they developed with the communities and local agencies. Two types of projects were put forward as tests of the community design process developed in collaboration by CPID. The first, under a continuation of the SACOG contract were community based bus stations, one at Del Paso Heights, one of the two original pilot communities. The, second for Knights Landing, a rural community in the Sacramento region for which the bus stop needed to be more than a bus stop but rather lifeline services to the community. Lifeline services are increasingly a concern for rural communities where the majority of the population are families, in towns too small to support their essential needs (education, a grocery store, and recreation for their children and families). CPID's proposal for rethinking the bus shelter as an important community institution and service has been seen by these communities as a potential solution to this isolation, offering to build facilities within the community as part of the community while offering a vital stop for the buses that provide lifeline services to these communities through a connection to larger towns with the needed resources.

\section{COMMUNITY PROCESS: SCREEN DESIGN}

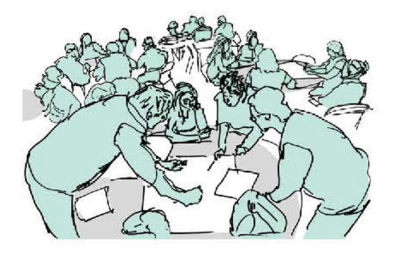

COMMUNITY PARTNERSHIPS
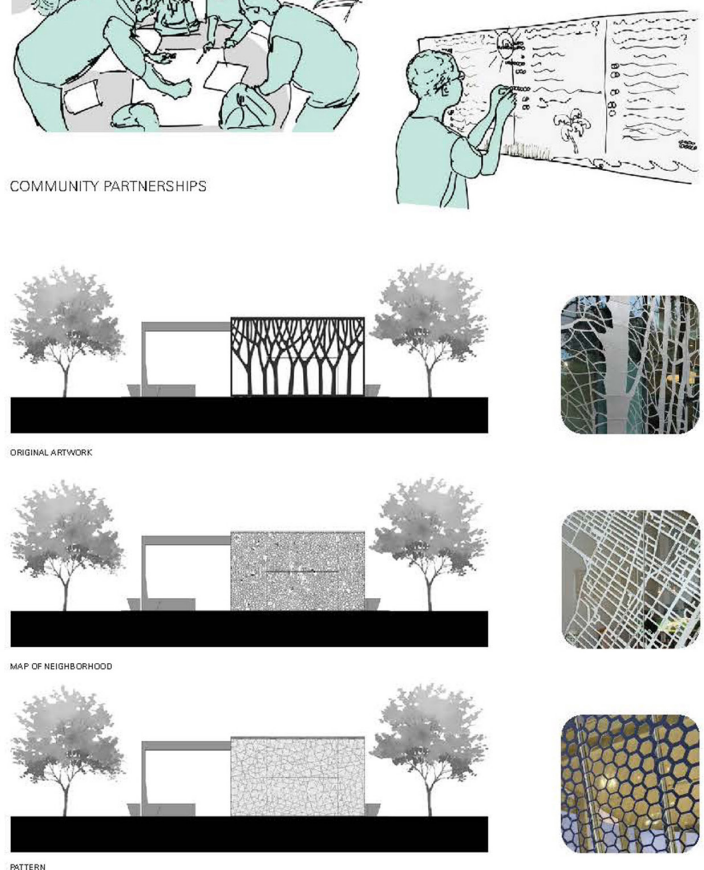

Figure 3. Bus station Proposed design process and opportunities. 
The Del Paso Heights bus stop will be completed as part of a larger urban redevelopment in the next few years. This stop will be placed on the site of another design studio investigation the CPID has conducted as part of this process, the creation of a competitive sports park in the area. The Del Paso Heights Sports Center (DPHSC) will serve as an economic generator by becoming a destination for hundreds of Californians outside of the neighborhood each weekend, and provide the valuable community amenity of a healthy and safe recreational facility that is desperately needed in the area. The bus stop will respond to community desire in its design while expressing the programmatic link of the DPHSC and the new Sacramento King's basketball arena downtown that are connected by the transit line.

These two first bus stop will test the larger system developed by the CPID, including the tools it has created to enable this process; a comprehensive manual that empowers communities to create their own transit stops, and an online tool that will provide opportunities for ongoing feedback about community desires, challenges, and opportunities, while documenting community needs to help stakeholders advocate for change. The online tool stems from the innovative work of Madrid-based design firm Ecosistema Urbano who have created participatory web-based platforms for a "networked design" approach on projects like Dream Hamar in Norway (Ecosistema Urbano, 2012). The firm has helped the CPID adapt one of these web-based tools for use in Sacramento, called With Sacramento. Consistent with the CPID's practice, the tools and systems developed during this process are intended to be expanded throughout Sacramento and beyond if proven to be successful.

This methodology, and approach, to guide participation by the disinvested communities targeted by the cap and trade legislation, was embraced by SACRT, the regional transit system, that in 2016 hired us to take this early work and transit guide and produce three light station designs based on our methodology. The first opportunity has come in the form of the design of the Dos Pasos light rail station. The station is a gateway facility to the Sacramento Rail Yards redevelopment project. The project is the largest urban development project in US and the station marks the symbolic entry to Sacramento. The redevelopment is potentially displacing several low income communities that have a long history in the area. Though they were offered the opportunity to be

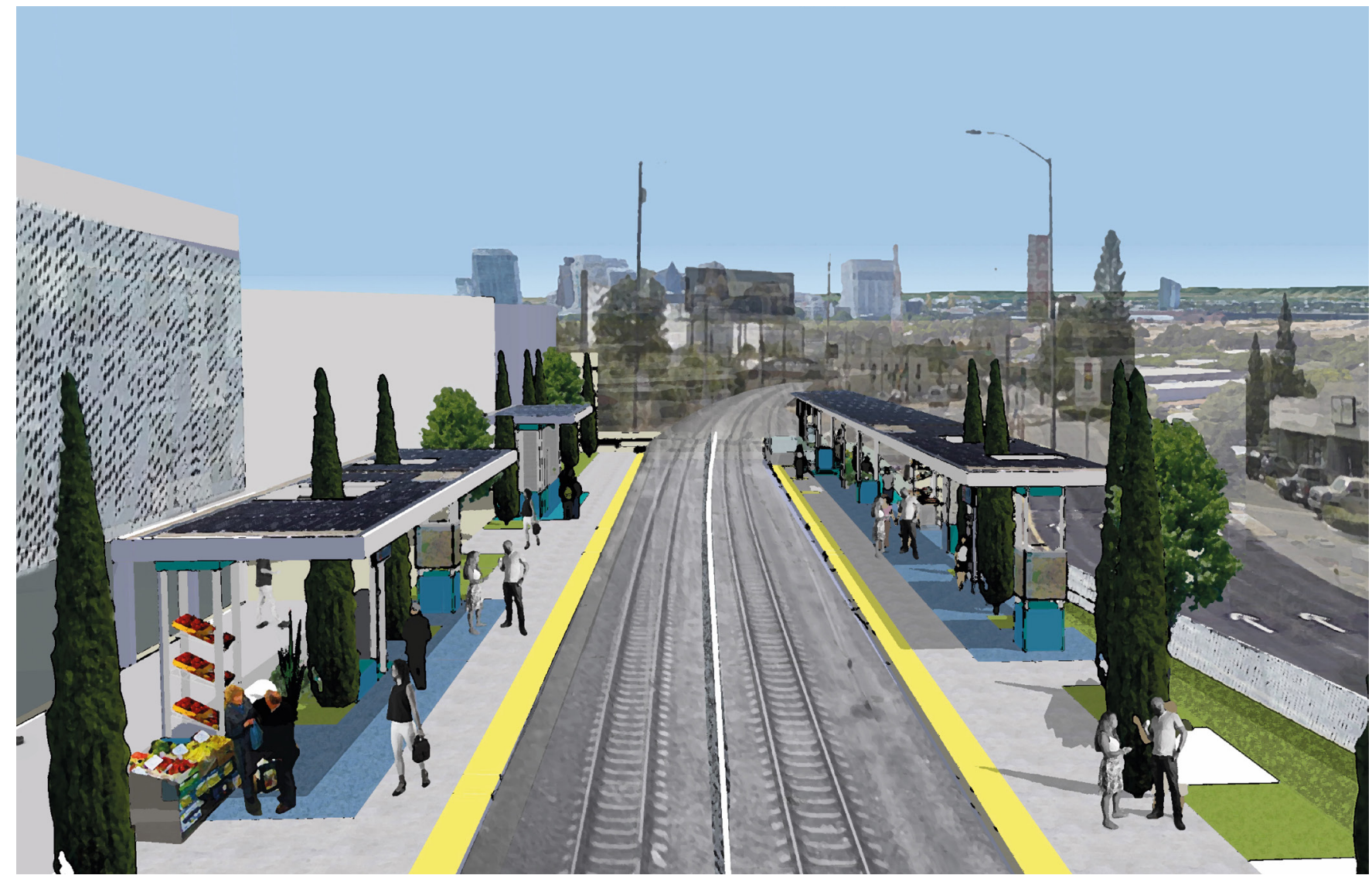

Figure 4. Dos Pasos Station design. 
first to receive the affordable housing being developed by SACOG and developers, many residents did not trust either the city or the developers to deliver on their promise and were contemplating moving out of an area that has been their home for generations. The CPID process therefore not only included them in the design process of the Dos Pasos station that will be added to their community but also in additional programming the station could provide to enhance their perceived needs and entice them to stay. Following the model of the 'bus station as community center', that has guided our bus transportation work for the region, the light rail station was designed to address essential needs currently missing as identified by the resident community. SOCOG, Sacramento's government agencies involved in guiding the larger scale urban development project of the rail yards, and architects representing the developer of the future housing at the station have also been included throughout the process. This coming to the table of the multi-stakeholders and agencies and developers, a process that was curated by CPID, has created a transparancy of process, and intentions, that has led to agreement on programming that has challenged the traditional notions of what constitutes a light rail station, and its role in urban development. One interesting outcome has been rethinking by the developer and city agencies of what is expected and should be included as amenities and facilities in the new housing adjacent to the station. The housing as a result of discussions between stakeholders been rethought of as an integral part of the station. The new station concept and design will jointly be offering space for both permanent and flexible programming community events and needs. These range from social vital social services needed by the resident community that will be accommodated in the housing's ground floor at the station, bike share programs, gardens, and flexible space able to accommodate fresh produce markets and cultural events. They will also include, for the first time in a generation, public bathrooms. Public bathrooms have become a contentious issue in public space development in California and nationally, both for their maintenance costs and the unwanted activities and users they can attract. But bathrooms are often a necessary need for both the community and those traveling long distances to work on the transit system. The public process that was developed during the charrette exchanges and activities eventually led to a consensus that was even supported by the business community in the area, who finally in conversation with the community for whom the bathrooms were an essential need realized the importance of offering this service to public.

The symbiotic relationship developed between the station and the housing extended to the use and sharing of solar energy, shared intermodal transportation options offered (for instance bicycle and car share programs charged by shared microgrids of solar power), and rainwater catchment systems feeding planting shared both by public and private developed spaces. This more enlightened view of what a station can offer and contribute to the public realm led to the station finally after many years, receiving a 21 million dollar grant from the State's cap and trade program, the first light rail station to receive funding under the program. Cited in the award was both the just mentioned synergy between station, public space and housing, as well as the support across stakeholders created by the process. What the process provided was a vision and consensus that was not possible by the established methods and procedures Sacramento had for development and transportation projects public process, and one in which all stakeholder of the project participated, and in doing so felt ownership of the results (Figure 4).

\section{CONCLUSION}

The Center for Public Interest Design's work in Sacramento represents an investigation into how designers might intersect with government agencies and community organizations to identify opportunities for strategic projects in disadvantaged communities funded through legislative initiatives. By working with stakeholders, the CPID has been able to propose interventions that amplify community voice in an effort to improve community and environmental health. By incorporating the work into architecture studios, students have learned to become more conscientious designers by involving the community in the process. The type of legislation being leveraged represents a significant opportunity for designers to apply their skills toward positive social impact in underserved communities. The approach of the CPID has been extremely well-received in the area, and the Center was able to expand its role in Sacramento through a partnership with Sacramento Regional Transit, and other regional transit authorities, on the design of several light rail stations and bus stations in underserved communities. While working with governmental organizations to identify opportunities for projects in historically marginalized communities made possible by funding available through complex legislation is not without its challenges, there is a significant need for designers to contribute to the process in order to make healthier places and people. When major developments in policy present themselves in situations like the creation of California's massive cap and trade program, designers need to be ready to use the power of design to ensure that the ensuing investments from these policy changes are made with meaningful vision, intent, and the co-authorship of stakeholders whose lives these investments will impact. As the work we have conducted for SACOG and SACRT has shown these participatory design processes can lead to additional outcomes and opportunities that might not be possible through traditional public processes. In these projects these additional opportunities and funds have benefited both the target communities and the public agencies sponsoring this work. 


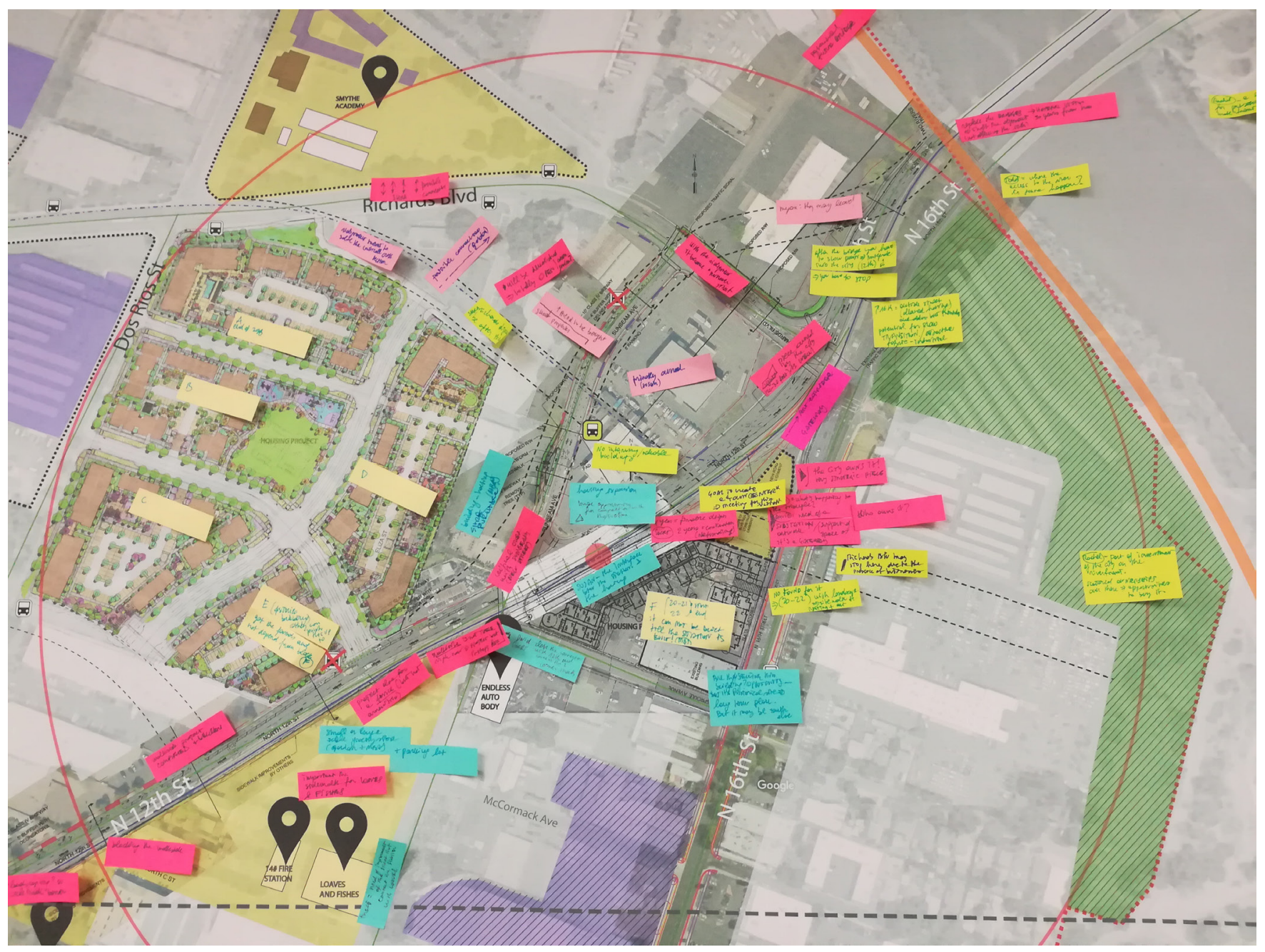

Figure 5. Mapping of agencies shared opinions and future plans for the site of the light rail station.

\section{ENDNOTES:}

1. The California Endowment created a web tool that allows Califronians to enter their zip code and see the average life expectancy in their area. That tool can be accessed here: www.calendow.org/news/your-zip-code-lifetime.

2. A 2012 article by Deborah Schoch for USC's Center for Health Reporting cov-ers this campaign in more depth. http://centerforhealthreporting.org/ blog/tale-two-cities-and-two-life-expectancies.

3. Burd-Sharps, Sarah and Kristen Lewis. A Portrait of California: California Human Development Report 2011. American Human Development Council, 2011.

4. This concept of zip codes as determinants of health is by no means isolated to California. A 2015 New York Times article by Sabine Tavenise and Albert Sun, "Same City, But Very Different Life Spans," discusses the phenomenon and provides infographics for several cities.

5. From the Califronia Climate Investments 2016 Annual Report.

6. CalEPA. California Communities Environmental Health Screening Tool, Version 2.0 (CALENVIROSCREEN 2.0), 2014.

7. Ibid. 